\title{
Optimized polymer enhanced foam flooding for ordinary heavy oil reservoir after cross-linked polymer flooding
}

\author{
Chen Sun ${ }^{1,3} \cdot$ Jian Hou ${ }^{1,2} \cdot$ Guangming Pan $^{2,4} \cdot$ Zhizeng Xia $^{2}$
}

Received: 27 September 2015/ Accepted: 13 December 2015/Published online: 8 January 2016

(C) The Author(s) 2016. This article is published with open access at Springerlink.com

\begin{abstract}
A successful cross-linked polymer flooding has been implemented in JD reservoir, an ordinary heavy oil reservoir with high permeability zones. For all that, there are still significant volumes of continuous oil remaining in place, which can not be easily extracted due to stronger vertical heterogeneity. Considering selective plugging feature, polymer enhanced foam (PEF) flooding was taken as following EOR technology for JD reservoir. For low cost and rich source, natural gas was used as foaming gas in our work. In the former work, the surfactant systems CEA/ FSA1 was recommended as foam agent for natural gas foam flooding after series of compatibility studies. Foam performance evaluation experiments showed that foaming volume reached $110 \mathrm{~mL}$, half-life time reached $40 \mathrm{~min}$, and dimensionless filter coefficient reached 1.180 when CEA/FSA1 reacted with oil produced by JD reservoir. To compare the recovery efficiency by different EOR technologies, series of oil displacement experiments were carried out in a parallel core system which contained cores with relatively high and low permeability. EOR technologies concerned in our work include further cross-linked polymer (C-P) flooding, surfactant-polymer (S-P) flooding, and PEF flooding. Results showed that PEF flooding had
\end{abstract}

Jian Hou

houjian@upc.edu.cn

1 State Key Laboratory of Heavy Oil Processing, China University of Petroleum, Qingdao, Shandong 266580, China

2 College of Petroleum Engineering, China University of Petroleum, Qingdao, Shandong 266580, China

3 College of Chemical Engineering, China University of Petroleum, Qingdao, Shandong 266580, China

4 Bohai Petroleum Research Institution, Tianjin Branch of CNOOC Ltd., Tianjin, China the highest enhanced oil recovery of $19.2 \%$ original oil in place (OOIP), followed by S-P flooding (9.6\% OOIP) and C-P flooding ( $6.1 \%$ OOIP). Also, produced liquid percentage results indicated PEF flooding can efficiently promote the oil recovery in the lower permeability core by modifying the injection profile.

Keywords Natural gas - Polymer enhanced foam flooding · Oil displacement experiment - Selective plugging

\section{Introduction}

Currently, chemical flooding has been widely used in ordinary heavy oil reservoirs in China (Zhou et al. 2006, 2013; Gao 2011; Hou et al. 2013a, b; Zhang et al. 2014). As one of the main techniques, cross-linked polymer flooding has been widely implemented for enhancing oil recovery of high water cut reservoirs and achieved good development effect (Urbissinova et al. 2010; Renouf 2014). Yet for all that, there are still significant volumes of oil remaining in place. In most cases, however, $40-50 \%$ of the original oil in place (OOIP) can not be easily extracted due to stronger reservoir heterogeneity and more complicated plane distribution characteristic. Along with further promotion and application of polymer flooding technology, similar remaining oil reserves will rise continually.

Many cases showed that it played a limited role in oil recovery improvement to continue using polymer as a profile control and flooding agent in different chemical methods after cross-linked polymer flooding, such as secondary cross-linked polymer flooding, surfactant-polymer (SP) flooding and alkali-surfactant-polymer (ASP) flooding. That is mainly due to the further development of thief 
channels. The number of thief channels increased and the distribution of remaining oil became more complex after the first cross-linked polymer flooding (Maghzi et al. 2014). Besides, stronger heterogeneity of post cross-linked polymer flooding reservoirs makes injected fluid prefer to flow through highly permeable thief channels, rather than displace the remaining oil in low permeability areas, where a mass of remaining oil locates as continuous state.

A successful cross-linked polymer flooding has been implemented in the target oil field (Yang et al. 2008), JD reservoir, an ordinary heavy oil reservoir with high permeability zones. After cross-linked polymer flooding, the distribution of remaining oil became more complicated and it was more difficult to use the chemical flooding which taking only polymer as a profile control for enhancing its oil recovery. Therefore, a new kind of profile control and flooding agent with greater sweep efficiency is of great importance for the development of post-polymer flooding reservoirs.

Foam flooding using foam generated by a mixture of gas (nitrogen, natural gas or other gases) and foaming agents as an oil displacement medium (Pang 2010; Chen et al. 2010; Li et al. 2010). A lot of works reported that enhanced foam flooding was widely used to further develop this kind of post-polymer flooding reservoirs (Li et al. 2009). Generally, nitrogen was used as foaming gas because of its good compatibility with foam agent (Zitha and Du 2010; Hou et al. 2013a, b). However, nitrogen supply needs to increase nitrogen production equipment, which is a big investment for the kind of high water cut reservoirs. There was rich natural gas produced by JD reservoir. Also for low cost and good economy, natural gas was used as foaming gas in our work. However, compared with nitrogen, it is more difficult to select foam agent for natural gas. In the former work (Pan et al. 2013), foam Agent CEA:FSA1(7:3) was selected for natural gas foam flooding. Considering the evaluation indexes of foaming capability, foam half-life time and interfacial tension, CEA:FSA1(7:3) and CEA:DHF-1(7:3) were chosen by laboratory experiments conducted under simulated water-oil conditions of JD Reservoir. And, further foam performance evaluation experiments showed that CEA:FSA1(7:3) has better oil tolerance ability, anti-adsorption ability and aging resistance ability. CEA:FSA1(7:3) was recommended as foam agent for natural gas foam flooding in JD Oilfield and the concentration was optimized as $0.5 \%$.

In the work, EOR technologies concerned in our work included further cross-linked polymer (C-P) flooding, surfactant-polymer (S-P) flooding, and polymer enhanced foam (PEF) flooding. It was necessary to optimize the best EOR technology for JD oilfield, and characterize the potentiality of polymer enhanced foam (PEF) flooding for the kind of post cross-polymer flooding reservoirs.

\section{Experimental}

\section{Experimental equipments}

Chemical flooding displacement experiment system produced by the American TEMECO was used in the experiments. The experimental equipments included a gas-liquid injection system, the temperature control and pressure sensor system, the core clamping system and the separation and measurement system of produced fluid. The gas-liquid injection system was used to provide the fluid conditions for the chemical flooding experiments. Four kinds of fluid including polymer, surfactant, oil and formation water can be simultaneously injected. Also, the gas can be injected at the designed speed. The fluid and gas can be injected to the core clamping system, which included two cores with different permeability. This kind of design can reflect the vertical heterogeneity of real reservoirs. The temperature control and pressure sensor system can make sure that the experiments were carried out in the designed condition. The separation and measurement system was used to automatically segregate and measure the fluid produced at the core outlet.

The experimental procedure was shown in Fig. 1. The following ten items were included in the apparatus: (1) microscope constant-flux pump; (2) control apparatus of gas mass flow; (3) high-pressure gas tank; (4) storage tank of fluid agent; (5) pressure sensor; (6) two core models with different permeability; (7) back-pressure control device; (8) temperature control box; (9) separation apparatus; and (10) measurement apparatus.

In the chemical flooding selection experiments, the accuracy of the temperature was $\pm 0.5^{\circ} \mathrm{C}$, the flow rate was limited to $0-30 \mathrm{~mL}$ in the control apparatus of gas mass flow, the pressure was limited to the range of 0-10 $\mathrm{MPa}$ in the back-pressure valve and the pressure-controlling accuracies of both the back-pressure valve and digital pressure gauge were $0.01 \mathrm{MPa}$.

\section{Materials}

Materials used in experiments included natural gas, crude oil, AS-polymer, JRJL-3 crosslinker, JRJL-3 modifier, and surfactants. The natural gas and crude oil came from well G104-5 in JD reservoir. The crude oil had a viscosity of $95 \mathrm{mPa}$ s and a density of $0.82 \mathrm{~g} / \mathrm{cm}^{3}$. The component analysis result of natural gas was listed in Table 1.

The JRJL-3 crosslinker, JRJL-3 modifier, AS-polymers were supported by JD oilfield. The JRJL-3 crosslinker, JRJL-3 modifier, AS-polymers were used in the actual cross-linked polymer (C-P) flooding process of JD 
Fig. 1 Experimental procedure for chemical flooding selection

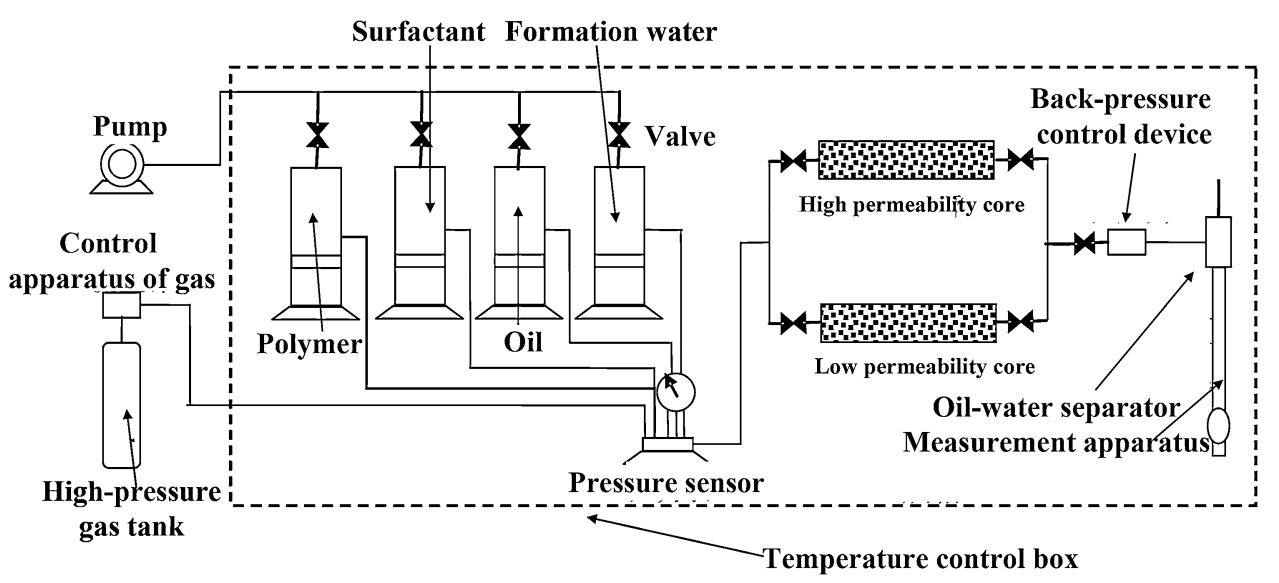

Table 1 Component analysis result of natural gas

\begin{tabular}{llll}
\hline Components & $\begin{array}{l}\text { Volume } \\
\text { percentage/\% }\end{array}$ & Components & $\begin{array}{l}\text { Volume } \\
\text { percentage/\% }\end{array}$ \\
\hline Methane & 71.68 & Isopentane & 0.28 \\
Ethane & 11.47 & $N$-pentane & 0.27 \\
Propane & 6.67 & Hexane & 0.17 \\
Iso-butane & 0.86 & Carbon dioxide & 0.19 \\
$N$-butane & 1.38 & Nitrogen & 7.03 \\
\hline
\end{tabular}

reservoir. The surfactant system, CEA:FSA1(7:3), was screened in our former work. And it has good compatibility with natural gas. The physical properties of main chemical agents involved in the work were listed in Table 2.

The parallel core system which contained cores with relatively high and low permeability. The parallel core system was a sand-packed tube model of $30 \mathrm{~cm}$ in the length and $2.5 \mathrm{~cm}$ in the diameter. The sand used in this work was siliceous sand, eighty percent of which in size was between 45 and 50 mesh. For each test, fresh sand was packed to ensure the same wettability. The following procedure was sand packing. And then measure the air permeability of the model. The absolute permeability of high permeability core was approximately $2500 \times 10^{-3}$ and $600 \times 10^{-3} \mu \mathrm{m}^{2}$ in the low permeability core. Then saturate the model with brine water. Water-saturated process continued for $5 \mathrm{~h}$, and the following oil-saturated process continued for more than $10 \mathrm{~h}$. The oil saturation of models was absolute $80 \%$ after oil-saturated process. The parallel core parameters are listed in Table 3.

\section{Experimental procedure}

\section{Scheme design}

Four experimental schemes were designed in this study, as shown in Table 4. Each experiment had the first crosslinked polymer flooding process. After the first crosslinked polymer flooding process, EOR technologies concerned in our work included further water flooding, crosslinked polymer (C-P) flooding, surfactant-polymer (S-P) flooding, and polymer enhanced foam (PEF) flooding. Injection parameters of different chemical methods for each scheme were illustrated in Table 5.

As a comparative experiment, there was no chemical agent injected in the further water flooding experiment. The chemical agent used in the further cross-linked polymer (C-P) flooding was same with the actual cross-linked polymer in JD reservoir. The surfactant agent used in the further surfactant-polymer (S-P) flooding and polymer enhanced foam (PEF) flooding was CEA:FSA1(7:3), which was selected for natural gas in our former work. Foam performance evaluation experiments showed that CEA:FSA1(7:3) had good oil tolerance ability, anti-adsorption ability and aging resistance ability. These experiments were conducted at a temperature of $65{ }^{\circ} \mathrm{C}$ and the injection rate was set to $0.5 \mathrm{~mL} / \mathrm{min}$.

\section{Experimental procedure}

There were four procedures in the four experiments, including experimental apparatus connection, sand-packed

Table 2 Physical properties of chemical agents

\begin{tabular}{|c|c|c|c|c|c|c|c|c|}
\hline $\begin{array}{l}\text { Cross-linked } \\
\text { polymer }\end{array}$ & $\begin{array}{l}\text { Molecular } \\
\text { weight } \\
\text { / }\end{array}$ & $\begin{array}{l}\text { Polymer } \\
\text { content } \\
\%\end{array}$ & $\begin{array}{l}\text { Hydrolyzing } \\
\text { degree } \\
\%\end{array}$ & $\begin{array}{l}\text { Intrinsic } \\
\text { viscosity } \\
\mathrm{mL} / \mathrm{g}\end{array}$ & $\begin{array}{l}\text { Surfactant } \\
\text { system }\end{array}$ & $\begin{array}{l}\text { Effective } \\
\text { content } \\
\%\end{array}$ & $\begin{array}{l}\mathrm{PH} \\
\text { valve } \\
\text { / }\end{array}$ & $\begin{array}{l}\text { Density } \\
\mathrm{kg} / \mathrm{L}\end{array}$ \\
\hline AS polymer & $1.50 \times 10^{7}$ & 92 & 25 & 1700 & CEA:A1(7:3) & 45 & $7-8$ & $1.00-1.01$ \\
\hline
\end{tabular}


Table 3 Parameters of parallel cores for experiments

\begin{tabular}{lllll}
\hline $\begin{array}{l}\text { Methods after cross-linked } \\
\text { polymer flooding }\end{array}$ & $\begin{array}{l}\text { (a) Further water } \\
\text { flooding }\end{array}$ & $\begin{array}{l}\text { (b) Cross-link } \\
\text { polymer flooding }\end{array}$ & $\begin{array}{l}\text { (c) Surfactant- } \\
\text { polymer flooding }\end{array}$ & $\begin{array}{l}\text { (d) Enhanced } \\
\text { foam flooding }\end{array}$ \\
\hline $\begin{array}{l}\text { Model parameters } \\
\text { Porosity/\% }\end{array}$ & 34.8 & 34.6 & 35.7 & 33.4 \\
Permeability of high permeability core $/ 10^{-3} \mu \mathrm{m}^{2}$ & 2503 & 2494 & 2397 & 618 \\
Permeability of low permeability core $/ 10^{-3} \mu \mathrm{m}^{2}$ & 601 & 606 & 86.3 & 607 \\
Oil saturation/\% & 82.1 & 84.4 & 78.8 \\
\hline
\end{tabular}

Table 4 Experimental schemes

\begin{tabular}{|c|c|c|}
\hline Number & Name & Experiments \\
\hline a & l & Water flooding + first cross-linked polymer flooding + following water flooding \\
\hline $\mathrm{b}$ & $\mathrm{C}-\mathrm{P}$ & $\begin{array}{l}\text { Water flooding }+ \text { first cross-linked polymer flooding }+ \text { following water flooding }+ \text { cross-linked polymer } \\
\text { flooding }+ \text { following water flooding }\end{array}$ \\
\hline $\mathrm{c}$ & S-P & $\begin{array}{l}\text { Water flooding }+ \text { first cross-linked polymer flooding }+ \text { following water flooding }+ \text { surfactant-polymer }(S-P) \\
\text { flooding }+ \text { following water flooding }\end{array}$ \\
\hline $\mathrm{d}$ & PEF & $\begin{array}{l}\text { Water flooding }+ \text { first cross-linked polymer flooding }+ \text { following water flooding }+ \text { polymer enhanced foam }(P E F) \\
\text { flooding }+ \text { following water flooding }\end{array}$ \\
\hline
\end{tabular}

Table 5 Injection parameters of different chemical methods

\begin{tabular}{|c|c|c|}
\hline Chemical flooding & Injection system & $\begin{array}{l}\text { Pore } \\
\text { volume }\end{array}$ \\
\hline $\begin{array}{l}\text { First cross-linked polymer } \\
\quad \text { flooding }\end{array}$ & $\begin{array}{l}\text { AS polymer }(2000 \mathrm{mg} / \mathrm{L})+\mathrm{JRJL}-3 \text { crosslinker }(800 \mathrm{mg} / \mathrm{L})+\mathrm{JRJL}-3 \\
\text { modifier }(600 \mathrm{mg} / \mathrm{L})\end{array}$ & 0.2 \\
\hline Further cross-linked polymer flooding & $\begin{array}{l}\text { AS polymer }(2000 \mathrm{mg} / \mathrm{L})+\mathrm{JRJL}-3 \text { crosslinker }(800 \mathrm{mg} / \mathrm{L})+\mathrm{JRJL}-3 \\
\text { modifier }(600 \mathrm{mg} / \mathrm{L})\end{array}$ & 0.3 \\
\hline $\begin{array}{l}\text { Surfactant-polymer (S-P) } \\
\quad \text { flooding }\end{array}$ & AS polymer $(2000 \mathrm{mg} / \mathrm{L})+\mathrm{CEA}: \mathrm{A} 1(7: 3)(0.5 \%)$ & 0.3 \\
\hline Polymer enhanced foam (PEF) flooding & $\begin{array}{l}\text { AS polymer }(1500 \mathrm{mg} / \mathrm{L})+\text { surfactant }[\mathrm{CEA}: \mathrm{A} 1(7: 3)](0.5 \%)+\text { natural } \\
\text { gas (gas liquid ratio } 1: 1)\end{array}$ & 0.3 \\
\hline
\end{tabular}

model preparation, first cross-linked polymer flooding and further chemical flooding. Following are details.

1. Experimental apparatus connection

Connect the experimental apparatus according to Fig. 1.

2. Sand-packed model preparation

Saturate the sand-packed model with water, and flood the model with oil until the irreducible water saturation was reached.

3. First cross-linked polymer flooding

(1) Water flooding

Flood the model with water at a constant rate until the water cut of outlet reaches $94 \%$.

(2) First cross-linked polymer flooding
Inject cross-linked polymer system of $0.2 \mathrm{PV}$ into the parallel core system at a constant rate.

\section{(3) Following water flooding}

Flood the model with water at a constant rate until the water cut of outlet reached $97 \%$.

4. Further chemical flooding

(1) Chemical slug injection

Inject the chemical slug of $0.3 \mathrm{PV}$ into the model at a constant rate according to Table 5 .

\section{(2) Following water flooding}

Flood the model with water at a constant rate until the water cut of outlet reached $98 \%$. End the experiment and prepare for the next one. 
Fig. 2 a Water cut and recovery curves of water flooding after crosslink polymer flooding. b Water cut and recovery curves of cross-link polymer flooding after cross-link polymer flooding. $\mathbf{c}$ Water cut and recovery curves of surfactant-polymer flooding after cross-link polymer flooding. d Water cut and recovery curves of enhanced foam flooding after cross-link polymer flooding. A Water flooding, $B$ first cross-linked polymer flooding, $C$ following water flooding until $97 \%$ water cut, $D$ following water flooding until $98 \%$ water cut (a), further cross-linked polymer flooding (b), surfactant-polymer flooding (c), enhanced foam flooding (d), $E$ following water flooding until $98 \%$ water cut

\section{Result analysis}

\section{Water cut and recovery curves}

The change curves of water cut and recovery in different chemical flooding experiments can reflect the development effect and potential EOR for the post cross-polymer reservoirs. The change curves of water cut and recovery in four different chemical flooding experiments was shown in Fig. 2a-d.

The cross-polymer flooding was carried out in all the four experiments when the water cut got $94 \%$ during the water flooding process. It can be seen that the recovery of four different experiments, respectively, reached 35.8, $34.8,32.6$ and $29.3 \%$ before the cross-polymer flooding was carried out. Then 0.2 PV of cross-polymer fluid was injected in every experiment followed by water flooding until the water cut reached $97 \%$. At the time, the recovery of four different experiments reached 53.2, 52.9, 52.1, $50.4 \%$, respectively. Each experiment has the roughly same amount of remaining oil before the cross-polymer flooding and after that. And the enhanced oil recovery of the four different experiments respectively reached 17.4, $18.1,19.5$, and $21.1 \%$ during the cross-polymer flooding process.

It was different for the four experiments in the post cross-polymer flooding process. As a comparative experiment, there was no chemical agent injected in the experiment (a). And the water cut curve kept increasing until the end with the final recovery of $53.7 \%$. Cross-polymer solution slug of $0.3 \mathrm{PV}$ was injected followed by water flooding until the water cut reached $98 \%$ in the experiment (b). During the secondary cross-polymer flooding, the water cut curve decreased to 88.1 with $8.9 \%$ down. Compared with the recovery before the secondary crosspolymer flooding, the final recovery at the end of experiment (b) reached 59.0 with $6.1 \%$ increased. Surfactantpolymer solution slug of $0.3 \mathrm{PV}$ was injected followed by water flooding until the water cut reached $98 \%$ in the experiment (c). During the surfactant-polymer flooding, the water cut curve decreased to 63.4 with $33.6 \%$ dropped. Compared with the recovery before surfactant-polymer
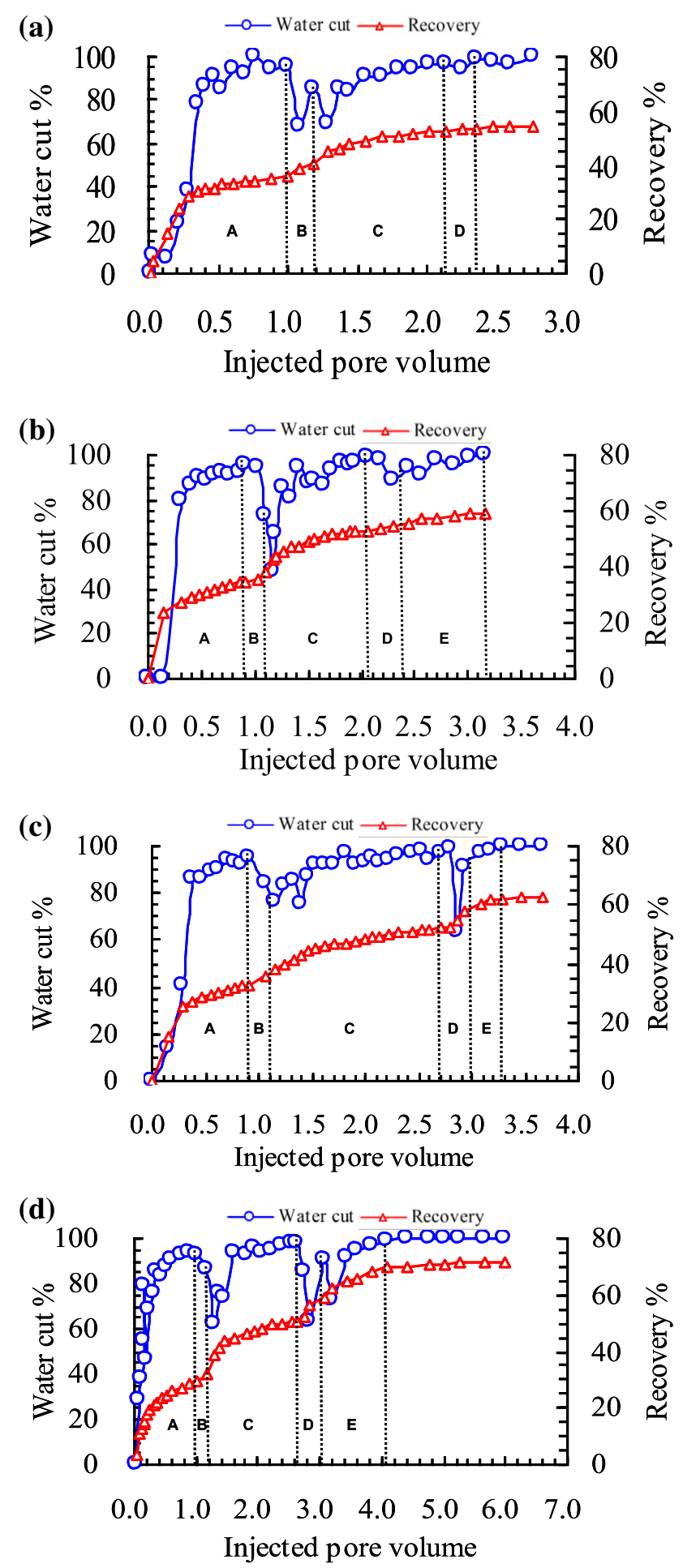

flooding, the final recovery at the end of experiment (c) reached 61.7 with $9.6 \%$ increased. Surfactant-polymer solution slug of $0.3 \mathrm{PV}$ and natural gas with 1-1 gas liquid ratio were injected followed by water flooding until the water cut reached $98 \%$ in the experiment (d). During the enhanced foam displacement stage, the water cut curve 


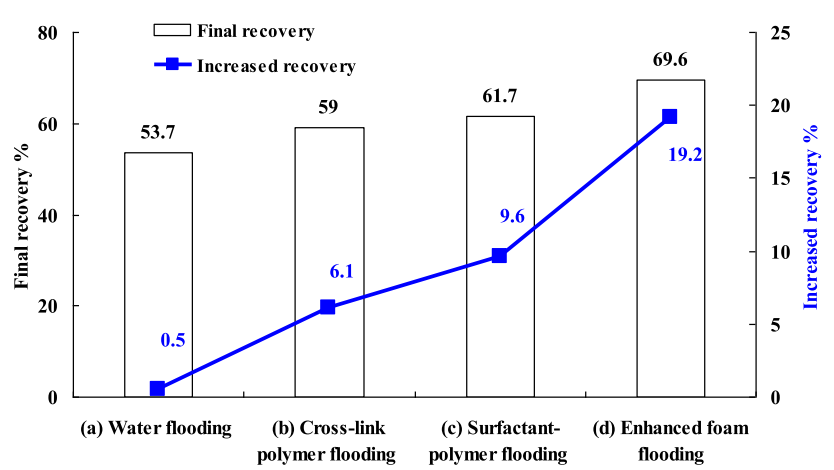

Fig. 3 Final recovery and increased recovery for chemical methods after cross-link polymer flooding

decreased $33.4 \%$ with the most wide water drop funnel. Compared with the recovery before enhanced foam flooding, the final recovery at the end of experiment (d) reached 69.6 with $19.2 \%$ increased. It can be concluded that the enhanced foam flooding had the best EOR effect for the post cross-polymer flooding reservoirs. The final recovery and increased recovery for chemical methods after crosslink polymer flooding was shown in Fig. 3.

\section{Liquid fraction comparison}

Liquid fraction of cores means the flow rate ratio at the outlet of the high permeability and low permeability cores. It can characterize the chemical profile blocking effect. The liquid fraction comparison of high permeability core and low permeability core in the four experiments was shown in Fig. 4a-d.

From the initial stage of four experiments, it can be seen that the liquid fraction of high permeability core remain at more than $90 \%$, while less than $10 \%$ for the low permeability core. Compared with the low permeability core, the injected water preferred to flow in the high permeability core at the same pressure difference. With the thief zone formed in the high permeability, there was more and more fluid flowing in the high permeability core, and there was less and less injected fluid flowing in the low permeability. The water cut of experiments got higher and higher. Then cross-polymer fluid of $0.2 \mathrm{PV}$ was injected in every experiment followed by water flooding until the water cut reached $97 \%$. The cross-polymer solution preferred to flow in the thief zone of high permeability core, and played plugging effect. It can be seen that the liquid fraction of the high permeability core decreased, while the liquid fraction of low permeability increased during the cross-polymer flooding process in the four experiments. During the following water flooding stage after the first crosspolymer flooding, the new thief zone was formed and the liquid fraction of high permeability core increased to more
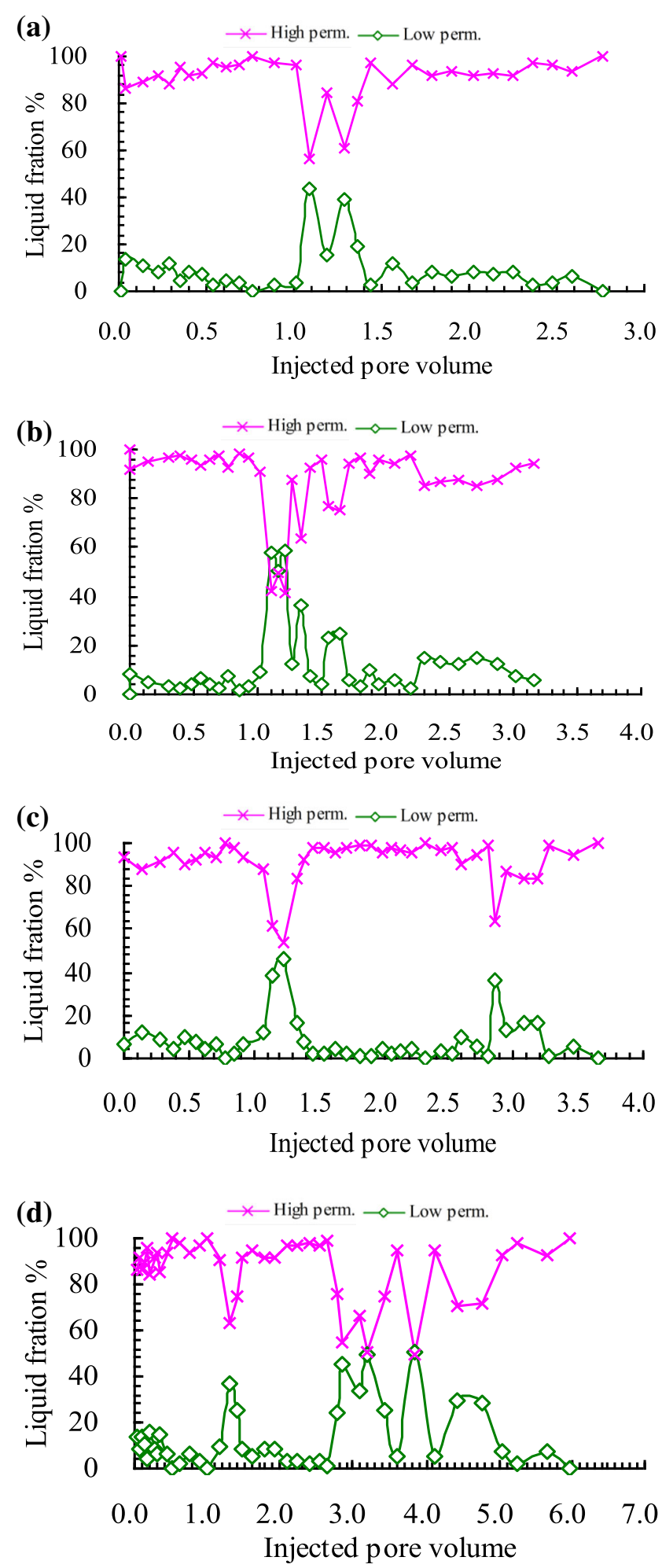

Fig. 4 Liquid fraction curves of high and low permeability cores for a water flooding after cross-link polymer flooding, b cross-link polymer flooding after cross-link polymer flooding, c surfactantpolymer flooding after cross-link polymer flooding, $\mathbf{d}$ enhanced foam flooding after cross-link polymer flooding 


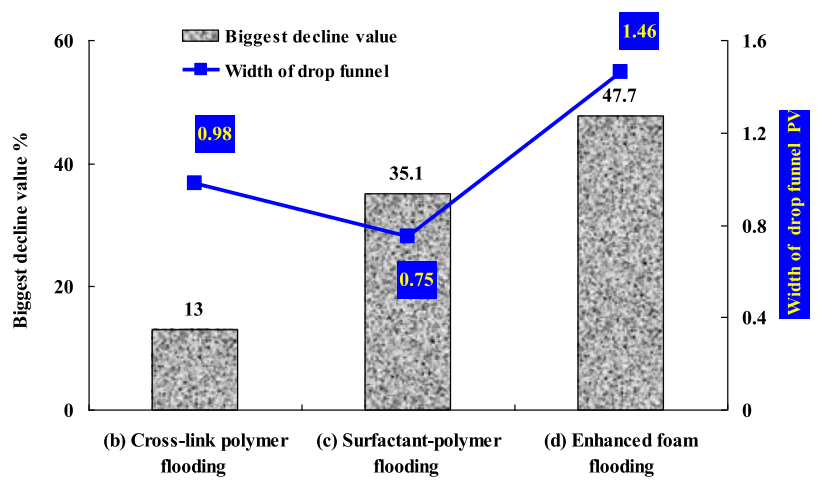

Fig. 5 Biggest decline value and width of drop funnel for chemical methods after cross-link polymer flooding

than $90 \%$. Meanwhile, there was fluid of less than $10 \%$ flowing through the low permeability core. In the post crosspolymer flooding process, liquid fraction curves of high and low permeability cores for the four experiments were different because different chemical fluid was injected in the four experiments. As a comparative experiment, there was no chemical agent injected in the experiment (a). And the liquid fraction of high permeability core kept increasing until the end with the final fraction of $100 \%$. The change trend of liquid fraction in the low permeability was opposite with that in the high permeability. In the post cross-polymer flooding process, further cross-polymer solution slug of $0.3 \mathrm{PV}$ was injected in the experiment (b). As shown in Fig. 4b, a drop funnel of liquid fraction in high permeability core was formed during the further cross-linked polymer flooding stage. The liquid fraction of high permeability core decreased from 97.8 to $84.8 \%$ with the biggest decline value of $13.0 \%$. And then the liquid fraction of high permeability core increased slowly along with the PV number of following water flooding increased. In the further cross-linked polymer flooding process, the width of the funnel was $0.98 \mathrm{PV}$. The biggest decline value and the width of the drop funnel reflect the selective plugging effect of different chemical methods. In the experiment (c), surfactant-polymer solution slug of $0.3 \mathrm{PV}$ was injected. In the experiment (d), surfactant-polymer solution slug of $0.3 \mathrm{PV}$ and natural gas with 1-1 gas liquid ratio were injected. The biggest decline value and the width of the drop funnel of experiment (b-d) were shown in Fig. 5. It can be seen that there was the biggest decrement $(47.7 \%)$ in experiment (d), also the decrement last the longest PV (1.46 PV). It indicated that the enhanced foam flooding had the best selective blocking effect for the post cross-polymer flooding reservoirs.

\section{Recovery comparison}

Liquid fraction of cores can characterize the chemical profile blocking effect. However, it cannot reflect the displacement oil ability of chemical agent in different experiments for the post-polymer flooding reservoirs. The recovery comparison of high permeability core and low permeability core in the four experiments was shown in Fig. 6a-d.

It can be found that the recovery of high permeability core was obviously higher than low permeability core in each experiment. From experiment (a) to experiment (b), the recovery of high permeability core were $76.5,74.4$, $80.1,74.6 \%$. Figure 7 gave the increased recovery of high permeability and low permeability cores for chemical methods after cross-link polymer flooding. Compared with the cross-polymer flooding process, the increased recovery of high permeability core were $2.8,1.6,7.2,11.5 \%$, respectively. The enhanced oil recovery of experiment (c) and experiment (d) were higher, which indicated that CEA:A1(7:3) system screened had a good ability to displace oil because of its good ability to reduce the interfacial tension. From experiment $(\mathrm{a}-\mathrm{b})$, the recovery of low permeability core was $33.2,44.1,44.0,58.4 \%$. Compared with the cross-polymer flooding process, the increased recovery of low permeability core were $0.7,10.4,11.9,26.6 \%$, respectively. The enhanced oil in the further cross-polymer flooding experiment mainly come from the low permeability core. Compared with the cross-polymer flooding experiment, there was no big difference in the recovery of low permeability core of the surfactant-polymer flooding experiment. It indicated that the surfactant injected did not play good washing oil effect in the low permeability core. Surfactant-polymer solution slug of $0.3 \mathrm{PV}$ and natural gas with 1-1 gas liquid ratio were injected followed by water flooding until the water cut reached $98 \%$ in the experiment (d). Foam with a high apparent viscosity formed in the high and low permeability cores during the injection process. And it played the role of selectively blocking in the high permeability core, and displaced the oil in the low permeability core at the same time. Also, as surfactant with good ability of reducing interfacial tension in the enhanced foam system, CEA:A1(7:3) can increase capillary number, accordingly, reduce saturation of irreducible oil and enhance oil recovery in the high and low permeability cores. Based on the above analysis, enhanced foam system can simultaneously enlarge sweep volume and increase washing efficiency in the high and low permeability cores. Considering selective plugging feature and good washing oil ability, polymer enhanced foam (PEF) flooding was taken as following EOR technology for JD reservoir.

\section{Conclusion}

1. To compare the recovery efficiency by different EOR technologies, series of oil displacement experiments were carried out in a parallel core system which contained 

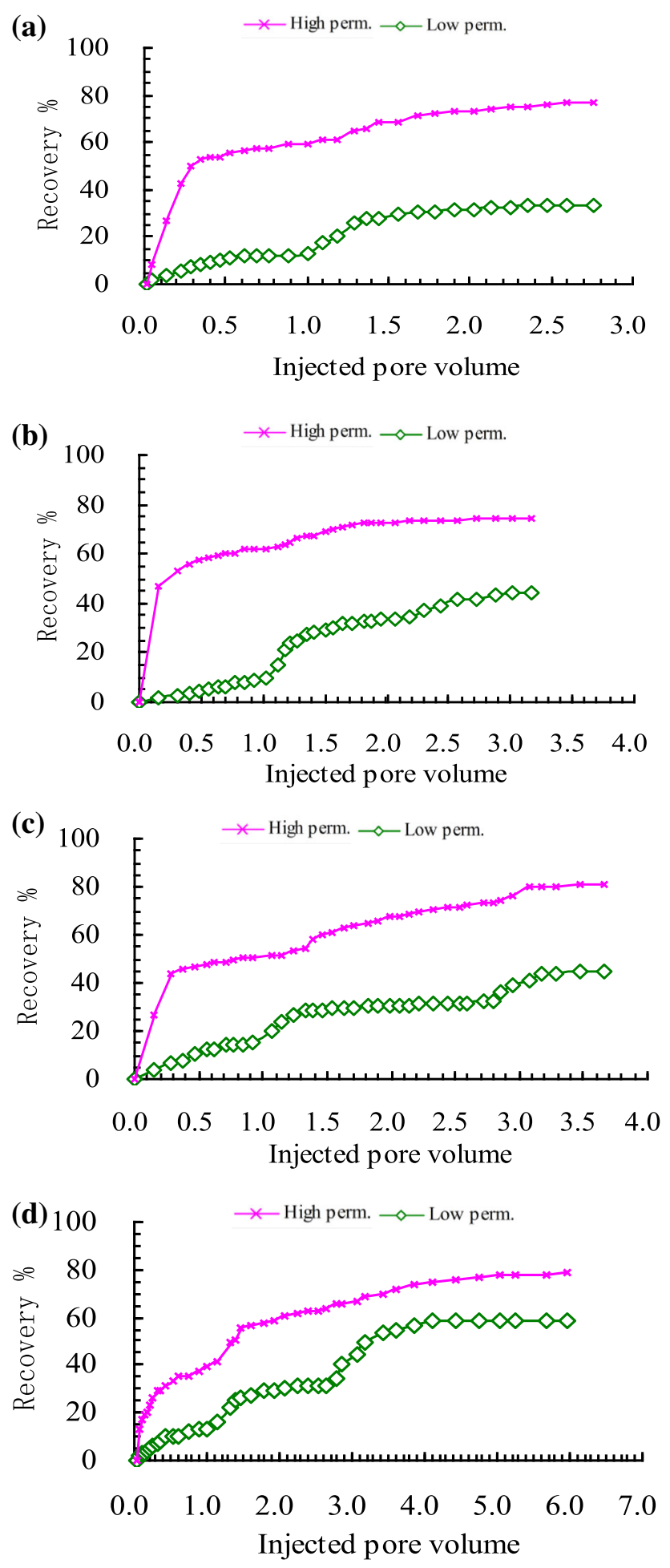

Fig. 6 Recovery curves of high permeability and low permeability cores for a water flooding after cross-link polymer flooding, b crosslinked polymer flooding after cross-link polymer flooding, $\mathbf{c}$ surfactant-polymer flooding after cross-link polymer flooding, $\mathbf{d}$ enhanced foam flooding after cross-link polymer flooding

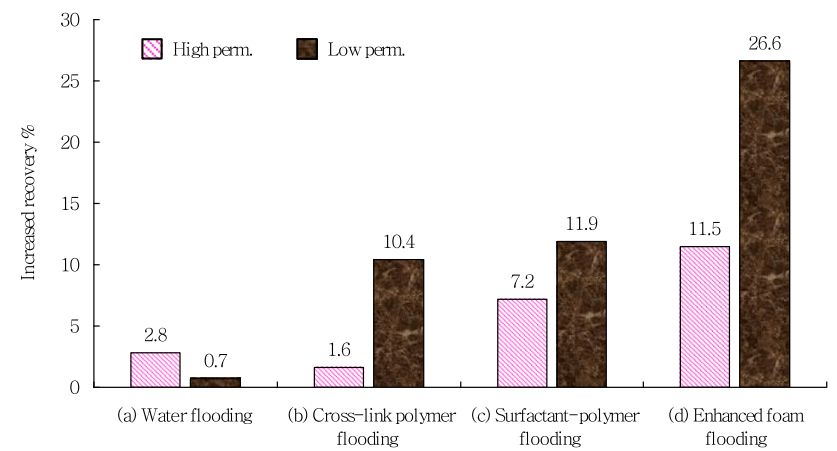

Fig. 7 Increased recovery of high permeability and low permeability cores for chemical methods after cross-link polymer flooding

cores with relatively high and low permeability. EOR technologies concerned in our work include further crosslinked polymer (C-P) flooding, surfactant-polymer (S-P) flooding, and polymer enhanced foam (PEF) flooding. Results showed that PEF flooding had the highest enhanced oil recovery of $19.2 \%$ original oil in place (OOIP), followed by S-P flooding (9.6\% OOIP) and C-P flooding (6.1\% OOIP).

2. Produced liquid percentage results indicated PEF flooding can more efficiently promote the oil recovery in the lower permeability core by modifying the injection profile.

3. Considering selective plugging feature and good washing oil ability, polymer enhanced foam (PEF) flooding was taken as following EOR technology for JD reservoir.

Acknowledgments The authors greatly appreciate the financial support of the National Natural Science Foundation of China (Grant No. 51574269), the Important National Science and Technology Specific Projects of China (Grant No. 2016ZX05011-003), the Fundamental Research Funds for the Central Universities (Grant No. 15CX08004A, 13CX05007A, 13CX05016A, 14CX02035A) and the Program for Changjiang Scholars and Innovative Research Team in University (Grant No. IRT1294).

Open Access This article is distributed under the terms of the Creative Commons Attribution 4.0 International License (http:// creativecommons.org/licenses/by/4.0/), which permits unrestricted use, distribution, and reproduction in any medium, provided you give appropriate credit to the original author(s) and the source, provide a link to the Creative Commons license, and indicate if changes were made.

\section{References}

Chen Q, Gerritsen MG, Kovscek AR (2010) Modeling foam displacement with the local equilibrium approximation: theory and experiment verification. SPE J 15:171-183 
Gao CH (2011) Scientific research and field applications of polymer flooding in heavy oil recovery. J Pet Explor Prod Technol 1(2-4):65-70

Hou J, Du Q, Li Z, Pan G, Lu X, Zhou K (2013a) The texture characteristics of the foam flowing in porous media under high pressure. Flow Meas Instrum 33:68-76

Hou J, Pan G, Lu X, Wei C, Qiu M (2013b) The distribution characteristics of additional extracted oil displaced by surfactantpolymer flooding and its genetic mechanisms. J Petrol Sci Eng 112:322-334

Li Z, Song X, Wang Q, Zhang L, Guo P, Li X (2009) Enhanced foam flooding pilot test in Chengdong of Shengli oilfield: laboratory experiment and field performance. International petroleum technology conference, Doha. pp. 7-9

Li Z, Rossen WR, Nguyen QP (2010) Three-dimensional modeling of tracer experiments to determine gas trapping in foam in porous media. Energy Fuels 24:3239-3250

Maghzi A, Kharrat R, Mohebbi A, Ghazanfari MH (2014) The impact of silica nanoparticles on the performance of polymer solution in presence of salts in polymer flooding for heavy oil recovery. Fuel 123:123-132

Pan G, Hou J, Zheng J, Wang Q, Wu J, Gan X (2013) Optimization of natural gas foam flooding in Gaoqianbei reservoir of Jidong oilfield. Oilfield Chem 30:37-42 (In Chinese)
Pang Z (2010) The blocking ability and flowing characteristics of steady foams in porous media. Transp Porous Media 85:299-316

Renouf G (2014) A survey of polymer flooding in western Canada. In: SPE improved oil recovery symposium, Tulsa. pp. 12-16

Urbissinova TS, Trivedi JJ, Kuru E (2010) Effect of elasticity during viscoelastic polymer flooding: a possible mechanism of increasing the sweep efficiency. J Can Pet Technol 49:49-56

Yang Z, Li H, Shang J, Song Q, Xiang X (2008) Appraising the adaptability of cross-linking polymer used in shallow layers of Jidong oilfield. Offshore Oil 28:59-64 (In Chinese)

Zhang X, Guan W, Pan F (2014) Improving recovery efficiency of polymer flooding for middle and low permeability reservoirs in Daqing oilfield. In: SPE Asia Pacific oil and gas conference and exhibition, Adelaide. pp. 14-16

Zhou G, Song X, Wang Q, Guo P, Li X (2006) Application of foam combination flooding in Shengli oilfield. Pet Expl Dev 33:369-373 (In Chinese)

Zhou X, Dong M, Maini B (2013) The dominant mechanism of enhanced heavy oil recovery by chemical flooding in a twodimensional physical model. Fuel 108:261-268

Zitha PLJ, Du D (2010) A new stochastic bubble population model for foam flow in porous media. Transp Porous Media $83: 603-621$ 